\title{
Historia de la chupalla: sombrero de paja típico del campesino chileno
}

\author{
History of the chupalla: typical straw hat of the Chilean peasant \\ Emiliano Núñez y Pablo Lacoste ${ }^{1 *}$
}

\section{RESUMEN}

Se estudia el proceso histórico de nacimiento y desarrollo de la chupalla, sombrero de paja, típico del campesino chileno. La investigación se ha realizado a partir de documentos originales del Archivo Nacional, de los siglos XVII, XVIII y XIX. Se detecta que el sombrero de paja se comenzó a utilizar en Chile en la década de 1740, y adoptó el nombre de chupalla desde la década de 1820. Al principio, las chupallas eran sombreros ordinarios; pero la llegada de los sombreros de pita y de jipijapa (Ecuador), en la segunda mitad del siglo XVIII, impulsó a los campesinos chilenos a elaborar también una línea de chupallas finas, proceso iniciado a comienzos del siglo XIX. A partir de entonces comenzaron a convivir las dos calidades: chupallas ordinarias y chupallas finas. Durante tres siglos, los campesinos han mantenido viva esta tradición, la cual ha llegado hasta la actualidad.

Palabras clave: chupallas de paja, sombreros de fibras tejidas, productos típicos chilenos, patrimonio cultural

\begin{abstract}
We study the historical process of birth and development of the "chupalla", straw hat typical of the Chilean peasant. The research work has been made from original documents of the National Archive, from the 17th, 18th and 19th centuries. It is detected that the straw hat began to be used in Chile in the 1740s, and adopted the name of "chupalla" from the 1820s. At first, the "chupallas" were ordinary hats. But the arrival of the hats of pita and "jipijapa" hats (Ecuador), in the second half of the eighteenth century, encouraged the Chilean peasants to also make a line of fine sausages. The process begun at the beginning of the nineteenth century; since that moment they began to coexist the two qualities: ordinary and fine straw hats "chupallas". For three centuries, the peasants have kept alive this tradition, which has reached the present time.
\end{abstract}

Keywords: straw hats, woven fiber hats, Chilean typical products, cultural heritage.

\section{Introducción}

Las chupallas son sombreros campesinos de fibras trenzadas, muy difundidos en Chile, particularmente en el Valle Central. Representan un producto típico asociado a la vestimenta tradicional del huaso chileno, junto al chamanto de Doñihue y las espuelas de plata; forma parte también de la indumentaria típica latinoamericana, junto al sombrero de jipijapa (Ecuador), conocido como Panama Hat.

Las chupallas se lucen en el rodeo, certamen de destrezas ecuestres, que se ha convertido en el deporte más popular de Chile (su convocatoria de público supera a la liga de fútbol profesional).
Además, en el mes de septiembre, cuando la población chilena se engalana para celebrar las fiestas patrias, las chupallas se instalan en el centro del escenario cultural del país, junto la gastronomía típica: empanadas, arrollado huaso y mote con huesillos, animado con las bebidas típicas: chacolí, pipeño y chicha (Castro et al., 2016; Lacoste, et al., 2015).

Las chupallas han generado una activa artesanía, que actualmente se elabora en los talleres de los valles de Colchagua, Maule e Itata. El potencial de las chupallas ya ha sido detectado por el Estado de Chile, el que, por medio de diversos organismos ha impulsado iniciativas tendientes al fortalecimiento y desarrollo del producto, sobre

\footnotetext{
1 Universidad de Santiago de Chile, Providencia, Santiago de Chile.

* Autor por correspondencia: pablo.lacoste@usach.cl
} 


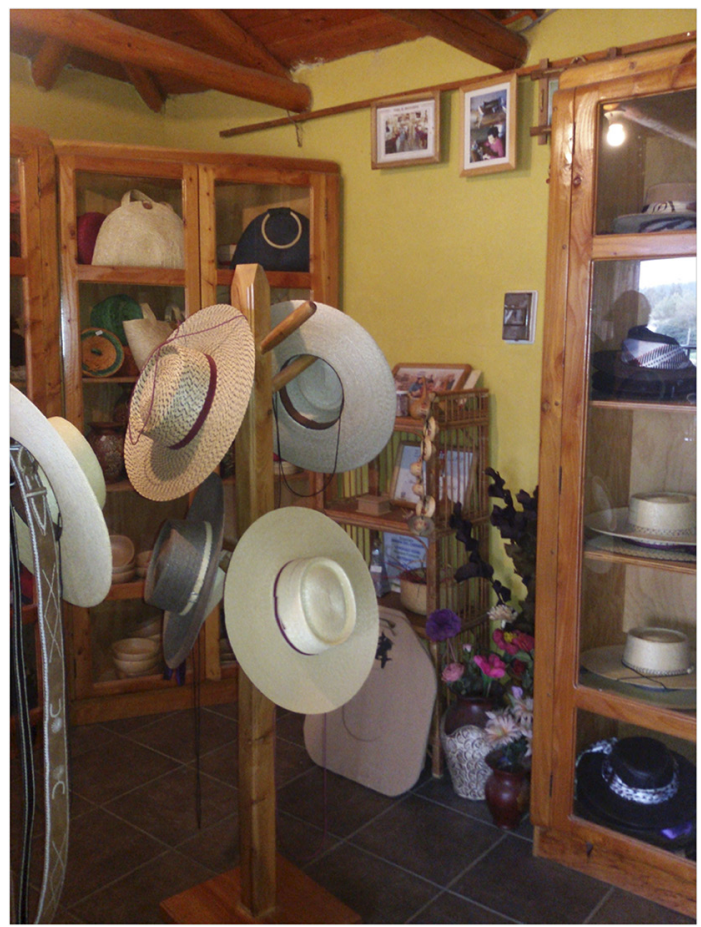

Figura 1. Chupallas en San Pedro de Alcántara. Foto Alexandra Kann.

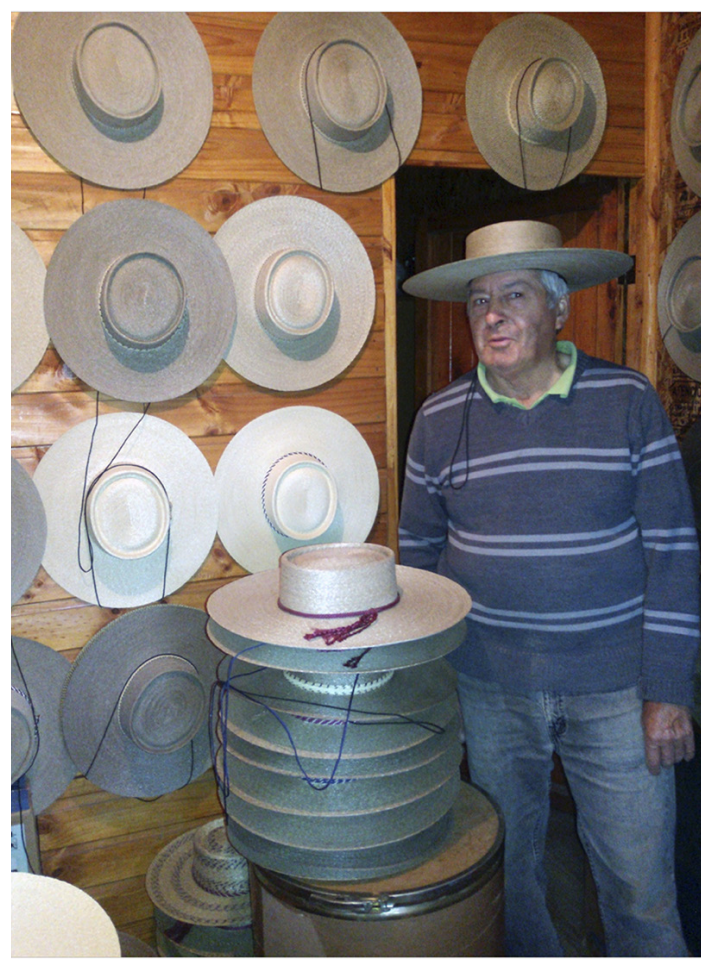

Figura 2. El maestro chupallero Aníbal Muñoz en su taller. Foto: Alexandra Kann.

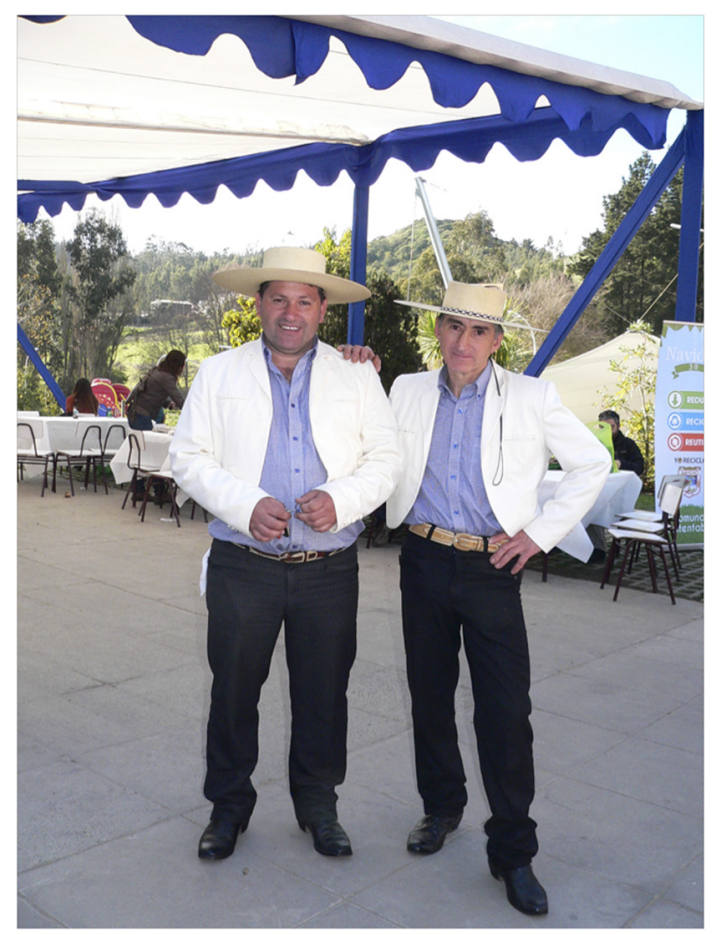

Figura 3. Artistas folklóricos chilenos con chupallas de San Pedro de Alcántara. Foto: Alexandra Kann.

todo desde el Ministerio de Agricultura, mediante la Fundación de Innovación Agraria (FIA) y del Ministerio de Economía, por medio del Instituto Nacional de la Propiedad Industrial (INAPI). Las chupallas de Ninhue (Región del Biobío) se encuentran en proceso de postulación al programa Sello de Origen del INAPI, para convertirse en Denominación de Origen; para ello cuentan con el apoyo de FIA para un proyecto ejecutado por la Universidad de Chile. Por su parte, el INAPI ha impulsado la valoración de las chupallas de La Lajuela y Santa Cruz (Cid, 2014). Y la Universidad de Santiago trabaja para valorizar las chupallas de San Pedro de Alcántara, Cutemo y La Lajuela, en un proyecto FIC del gobierno regional. Todos estos programas apuntan a valorizar, proteger y promover las chupallas como productos campesinos artesanales.

Así como el sombrero de jipijapa ha sido reconocido como Denominación de Origen en Ecuador, las chupallas chilenas también pueden alcanzar pronto esta jerarquía, con todo lo que ello implica en la valoración de los productos campesinos (Arancibia, 2016; Belmar, 2016). Se trata de trabajar en la valoración del producto, como propone 
Champredonde (2016). La dimensión histórica forma parte del valor simbólico del producto, tal como se ha examinado en Chile, para el queso de Chanco (Aguilera, 2016), los vinos de Codpa y Pintatani (Castro y Mujica, 2015), entre otros.

El presente artículo se propone examinar la evolución histórica de las chupallas en el territorio chileno, desde sus orígenes, en el siglo XVIII, hasta fines del siglo XIX, tiempo de madurez del producto. Para confrontar las hipótesis se han compulsado documentos originales del Archivo Nacional, particularmente inventarios de bienes de los siglos XVII, XVIII y XIX del Fondo Judiciales del corregimiento de Colchagua. En forma complementaria, se han contextualizado con documentos de esa época de los corregimientos de Aconcagua, Santiago y Cauquenes. También se han indagado los testimonios de los viajeros y cronistas de la época, tanto ingleses y norteamericanos como franceses y alemanes.

\section{El concepto de chupalla y su difusión en el campo chileno}

La palabra chupalla tiene sus raíces en la lengua quechua, oriunda del Perú y extendida a Chile durante la dominación inca. La palabra "chupalla" o "achupalla" se comenzó a utilizar como nombre vulgar de la Fascicularia bicolor, especie fanerógama de la familia Bromeliaceae. Esta planta tuvo una presencia importante en la vida social de los grupos humanos instalados en Chile, y muchas veces sirvió de referencia para identificar los lugares geográficos, lo que se reflejó en la toponimia.

La toponimia chilena ha generado numerosas localidades y asentamientos con el nombre de Chupallas o Achupallas. En la guerra de la independencia, cerca de Putaendo, se libró el "combate de Achupallas" (3 de febrero de 1817), en la garganta homónima. A comienzos del siglo XX se detectaron siete lugares con este nombre: tres caseríos (en Itata, Putaendo y Tabón), dos fundos (Itata y Villa Alegre), un cerro (Huentelauquén) y un portezuelo (Alicahue) (Riso Patrón, 1924). A ello se suma el cerro de Las Chupallas, en La Ligua (Archivo Nacional). Paralelamente, cerca de Viña del Mar se estableció el fundo Achupallas, el que fue vendido y loteado en 1950 para originar la localidad homónima actual, poblada por 40.000 habitantes. La persistencia del nombre Achupallas marca el profundo arraigo cultural del concepto en la población local. El sabor indígena de la palabra, debido a su origen quechua, la distingue del lenguaje español y la convierte en un símbolo de resistencia cultural y de identidad local.

Los sombreros de paja eran parte de la vida cotidiana de América Latina en el primer tercio del siglo XIX. Las elites los valoraban y usaban. El último gobernador realista del Reino de Chile, Casimiro Marcó del Pont, usaba balandre y chamanto con sombrero de jipijapa o de paja. Un coronel del Ejército de los Andes lo recordaba así: "vestía un uniforme de teniente general, calzón corto, medias de seda de patente, zapatos de terciopelo con hebillas de oro, un ponchito corto por encima y un sombrero muy fino de jipijapa" (Pueyrredón, 1862). Después de la batalla de Chacabuco, Marcó del Pont huyó hacia el litoral, y unos días después fue capturado en San Antonio, vestido con ese tipo de prenda: "le encontraron envuelto en un poncho balandrán y un disforme sombrero de paja" (Espejo, 1876). El general José de San Martín también utilizaba sombreros de paja. Después de sus En sus campañas libertadoras de Chile y Perú, San Martín regresó a su país vestido, precisamente, con un sombrero de paja. Así lo señaló el oficial que fue a recibirlo: "un riquísimo guarapón (sombrero de ala grande) de paja de Guayaquil cubría aquella hermosa cabeza" (Olazábal, 1864). Seguramente, lo había comprado en el puerto ecuatoriano el año anterior, durante su entrevista con Simón Bolívar. En armonía con ese sombrero típico, San Martín se presentó también abrigado por un chamal, antecedente inmediato del chamanto, fino tejido artesanal chileno. Este episodio, recogido por Olazábal en sus memorias, fue representado por el artista plástico Fidel Roig Matons, en el cuadro de composición Regreso del general San Martín y encuentro con Olazábal en el Portillo (óleo sobre tela en bastidor, $297 \mathrm{x}$ $205 \mathrm{~cm}$ ) (Figura 5), y el Estudio de Expresión para el cuadro anterior (óleo sobre hardboard, 40 x $54 \mathrm{~cm}$ ) (Figura 4).

El mundo del arte parece cada vez más sensible a representar a los héroes de la independencia con indumentarias típicas. Lo mismo se puede ver en la película de largometraje The Liberator, dirigida por Alberto Arvelo y protagonizada por Edgar Ramírez (2014). En este filme se utilizan sombreros de paja; los campesinos, ordinarios; 


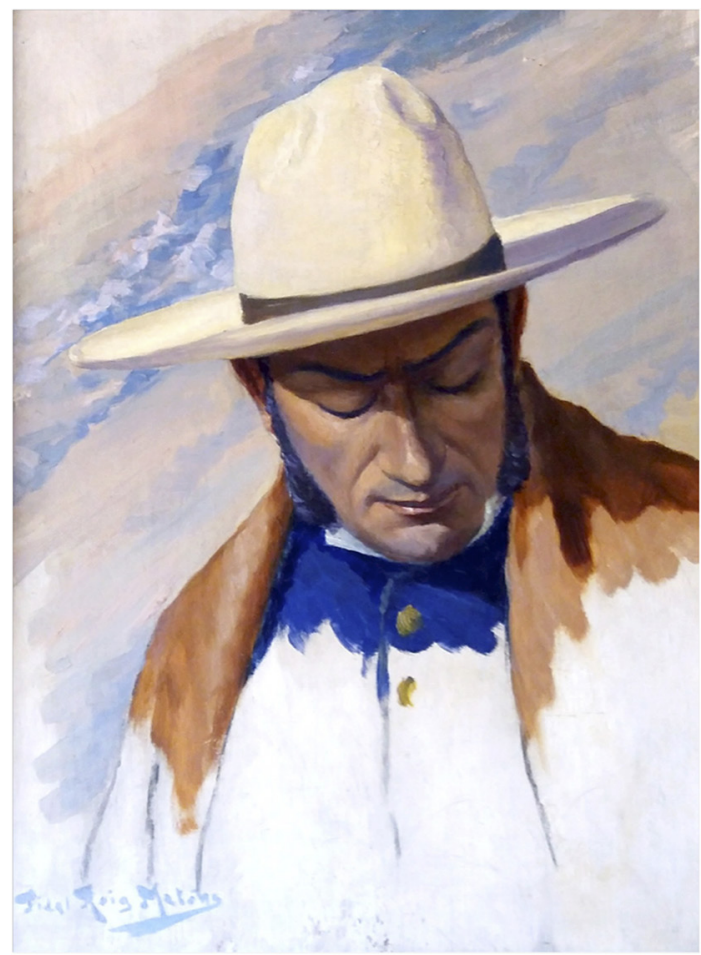

Figura 4. Fidel Roig Matons. Estudio de Expresión (óleo sobre hardboard, 40 x $54 \mathrm{~cm}$ ). Pinacoteca del Concejo Deliberante de Mendoza.

Simón Bolivar usa sombreros finos, como las elegantes chupallas chilenas.

La decisión de San Martín, de usar un sombrero de paja y un chamal en el momento de presentarse nuevamente en su patria, en febrero de 1823, no fue un hecho casual, sino parte de una estrategia general de los padres fundadores de las repúblicas americanas, en el sentido de valorizar y patrimonializar los productos típicos de los campesinos. Ello se reflejó también en otros momentos clave, como el banquete de la patria, celebrado el 16 de febrero de 1817 en casa de Juan Enrique Rosales, en Santiago, para festejar la victoria de Chacabuco. En ese banquete se sirvieron productos típicos chilenos como queso de Chanco, jamón de Chiloé, chacolí y asoleado de Cauquenes. Se mostraba así la voluntad de integrar a la elite patriota con el pueblo trabajador campesino. Algo parecido ocurrió al otro lado de los Andes, en el baile de la independencia, celebrado el 10 de julio de 1816 en la Casa de Tucumán. La elite rioplatense tuvo oportunidad entonces de conocer y apreciar el queso de Tafí del Valle, producto prestigioso en la zona desde comienzos del siglo XVIII. La presencia

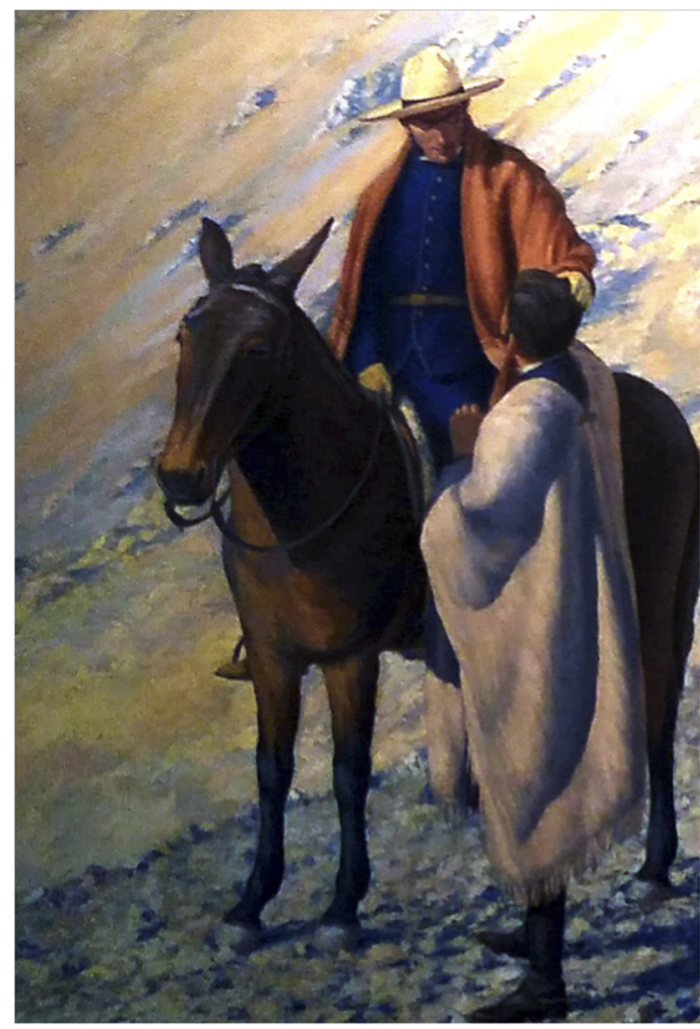

Figura 5. Fidel Roig Matons. Regreso del general San Martín y encuentro con Olazábal (fragmento) (óleo sobre tela en bastidor, 297 x $205 \mathrm{~cm}$ ). Pinacoteca del Concejo Deliberante de Mendoza..

del Congreso Nacional en la ciudad de Tucumán durante un año completo, permitió visibilizar ese producto típico local, y difundirlo al resto del país. En la década de 1820 se convirtió en un alimento muy valorado por las elites rioplatenses, según el ministro británico Woodbine Parish tal como se estudia en otra parte (Lacoste, 2017).

\section{Debates de chupallas y sombreros de paja}

El sombrero de paja como parte de la indumentaria típica chilena fue detectado por los viajeros extranjeros desde comienzos del siglo XIX. El británico Samuel Haigh (1817), el norteamericano William Ruschenberb (1834), el francés Max Radiguet (1847) y el alemán César Maas (1847) son buenos ejemplos.

El primero de ellos, al describir la indumentaria de los vecinos, destacó que "los hombres visten de diablos fuertes con ponchos y grandes sombreros de paja" (Haigh, 1817). El segundo destacó que "los arrieros también llevan sombreros de paja de 
forma cónica, poncho calzones hasta debajo de la rodilla, botas y grandes espuelas" (Ruschenberg, 1834). El tercero mencionó esta prenda como rasgo típico de la cultura chilena. "Los hombres usan un sombrero de paja, cuya punta termina en pan de azúcar y cuyos bordes presentan poca prolijidad" (Radiguet, 1847). Más adelante, el viajero galo dedicó una página al huaso chileno y aportó más detalles: "acostumbrado a vivir a todo sol, usa debajo del sombrero de paja un gran pañuelo de color con que se amarra la cabeza (Radiguet, 1847). Mayor precisión geográfica aportó el alemán Maas, para el que el río Maule establecía el límite cultural del sombrero: "La ribera opuesta del Maule tiene más vegetación. Atravesamos varias aldehuelas. Aquí ya se usan los bonetes, que hasta Valdivia son el privilegio de los campesinos, mientras que en todo el norte no se usan sino sombreros de paja o se envuelven la cabeza con un paño" (Maas, 1847). Es importante señalar que estas referencias corresponden al uso de sombreros de paja, sin abordarse todavía el concepto de chupalla.

La mirada de los viajeros varones se enriquece con el agudo testimonio de María Graham (1822). Ella tenía mayor capacidad de percibir y expresar los detalles, lo que permitió registrar datos más precisos sobre los sombreros que se usaban en Chile en esa época. Al referirse a "la clase decente entre los hombres", indicó que:

"el pelo se usa dispuesto en una gruesa trenza que cuelga por detrás, con un pañuelo de colores amarrado a la cabeza y encima un sombrero de paja, afianzado con un lazo negro. En algunos departamentos se usan sombreros de fieltro negro; en otros, unos altos bonetes" (Graham, 1822).

El testimonio de la viajera sirve para confirmar lo que señalaban sus colegas varones: el sombrero de paja estaba ampliamente usado en Chile en esos años, incluso en las elites. También destaca que el uso del sombrero tenía variaciones territoriales; en algunos lugares se usaban los bonetes, en otro, los sombreros negros; ella no indica con precisión en qué territorio se empleaba cada uno, como sí hizo Maas (1847).

El sombrero de paja para la elite lo usaban no solo los varones, sino también las mujeres. En un paseo, una mujer llamada Mariquita tenía "gorro negro de castor que le sienta admirablemente;
Rosario, sombrero de paja y rosas" (Graham, 1822). Desde el punto de vista social, el sombrero de paja estaba a la altura del gorro de castor, que durante el siglo anterior había dominado la escena entre las elites. Ello fue posible por el desarrollo de sombreros de paja de alta calidad, a la nivel de los más reputados.

Las primeras definiciones del concepto "chupalla" se realizaron en Chile entre fines de los siglos XIX y comienzos del XX (Rodríguez, 1875; Lenz, 1910). Más adelante aportó al tema Oreste Plath (1962). El primero de ellos aporta la siguiente definición: "sombrero de paja ordinario, un poco más puntiagudo de copa y corto de alas que el de pita, llamado también de jipijapa. Llámase probablemente chupalla del nombre indígena de la planta de cuyas hojas se elabora (achupalla)" (Rodríguez, 1875). Un siglo después, el tercer autor citado aporta algunos cambios, al definir chupalla: "voz quechua, chupallar, chupayas. Achupalla: planta bromeliácea (Agave), pita o maquey, con la cual se tejen grandes sombreros campesinos, por extensión llamados chupallas" (Plath, 1962). Entre ambas posiciones, es interesante la definición del segundo autor: "chupalla o (raro) sombrero de chupalla: sombrero ordinario de paja u otro material semejante del país. Hoy es cualquier sombrero de alas anchas usado por los huasos y también por gente acomodada en el campo; las hay de fabricación nacional tanto como importadas, ordinarias como de lujo. Primitivamente era el sombrero que más tarde se llamó de pita, y que hoy se llama de jipijapa hecho de la fibra de Agave americana" (Lenz, 1910).

Los tres autores aportan elementos interesantes, que permiten comenzar el análisis. El nombre "chupalla" proviene del lenguaje quechua, debido a la expansión del imperio inca en Chile. El segundo autor detecta una evolución del concepto, desde "sombrero de chupalla" a simplemente "chupalla". La primera expresión ya se encontraba en desuso en su momento (1910). Otra nota importante es el lazo con sombreros de América Central o de Ecuador (sombreros de pita o de jipijapa). Estos también se realizaban a partir de fibras trenzadas y se distribuyeron por todos los puertos del Pacífico Sur de América en los siglos XVIII y XIX. Los inventarios de bienes de las casas chilenas de esa época registraban con frecuencia los sombreros de pita o de jipijapa, lo mismo que las aduanas. Para un autor, los sombreros de pita y jipijapa precedieron a las chupallas (Lenz, 1910). 
La calidad y el significado social del sombrero también muestran algunos cambios en este tiempo. Al principio era un sombrero ordinario (Rodríguez, 1875). Pero más adelante, se produjo la diversificación, y comenzaron a coexistir simultáneamente, chupallas ordinarias con chupallas elegantes y finas (Lenz, 1910). En determinado momento, el sombrero perdió identidad, y se usó la palabra como genérico, para denominar todos los sombreros campesinos (Lenz, 1910). El origen del nombre sería la planta específica, agave, pita o maguey, pero luego se habría extendido a los sombreros campesinos de paja (Plath, 1962).

Los estudios previos mencionados constituyen un punto de partida interesante para examinar el tema. Pero es necesario indagar datos precisos en el terreno, para poder establecer con claridad el proceso histórico del surgimiento y evolución de estos productos típicos.

La tradición de las chupallas chilenas comenzó con la llegada de los españoles por dos elementos importantes: la cultura del sombrero y la incorporación del trigo como planta para su cultivo en el territorio. Antes de la llegada de los europeos, estos elementos no estaban presentes: los indígenas no usaban sombreros, y no existía el trigo en América. Pero esta situación comenzó a cambiar en la época colonial, período en el que se sentaron las bases para el desarrollo de este producto típico.

\section{La introducción del trigo en Chile y su expansión}

El trigo era uno de los pilares de la dieta mediterránea que los españoles introdujeron en Chile. La tríada vino-trigo-olivo formaba una unidad sociocultural, que los pueblos europeos trataron de mantener viva en las tierras conquistadas, según las posibilidades de climas y suelos. Y en la zona central encontraron lugares adecuados para ello, con lo cual, estos productos se propagaron con facilidad. En las haciendas de los siglos XVII y XVIII era habitual la presencia del trigo, para asegurar el abastecimiento de pan para la familia de los hacendados, sus criados, peones y esclavos. Así como el maíz había sido el cereal más importante del mundo indígena, y su base de alimentación, en el período colonial español, ese papel se transfirió al trigo.

El trigo y el vino fueron pilares de la economía colonial en Chile. Hacia mediados del siglo XVII, las 400 estancias chilenas producían entre 18 y 19.000 fanegas de trigo (Solórzano, 1657). La fuerte demanda del mercado peruano fue un estímulo constante de los trigos y harinas chilenas. Este impulso se expandió por todo el Valle Central, particularmente en el corregimiento de Colchagua. Este se extendía de cordillera a mar, desde los ríos Cachapoal y Rapel por el norte, hasta el río Teno y el estero Nilahue por el sur. El 7 de abril de 1779, el corregidor Antonio de Ugarte señaló que, con una población de 40.000 habitantes, la producción triguera de Colchagua era de entre 80.000 y 100.000 fanegas anuales. Ello representaba cerca de un tercio de la producción total chilena.

La producción triguera en Colchagua alcanzó una relevancia notable dentro de la economía regional. Ella representaba cerca de un tercio de la producción total chilena. La otra gran zona productiva se hallaba en el triángulo formado por San Felipe, Rancagua y Quillota, lugar que aportaba casi dos tercios del total chileno. Entre esos dos polos generaron los saldos exportables para abastecer el mercado peruano. Durante cerca de 250 años, el trigo fue la principal exportación chilena. En este contexto socioeconómico, florecieron las redes de molinos hidráulicos harineros, la tradición de la trilla y la cultura de la chupalla.

\section{Del sombrero de castor a la chupalla de paja}

La cultura del sombrero también se desarrolló a partir de la presencia de los conquistadores españoles. Las altas temperaturas de Colchagua, sobre todo en temporada estival, con $40^{\circ}$ centígrados, se combinaba con la mayor cantidad de días de sol en ese mismo período del año. Las lluvias de esta región suelen concentrarse en invierno. Por lo tanto, los veranos calurosos y soleados, generaban las condiciones para la valoración del sombrero.

En una primera etapa, los colonos españoles debían importar sombreros de otras regiones del imperio. Se usaban sombreros de piel de castor o de lana de vicuña; solían estar adornados con galones dorados y cintas plateadas; su precio oscilaba entre \$ 8 y \$14. Estos sombreros tenían significado social pues, por su alto precio, representaban una distinción entre los hacendados y el bajo pueblo. Además, estos sombreros servían para mitigar el 
frío en las mañanas de invierno, pero aportaban poca utilidad en las soleadas tardes de verano.

El sombrero de castor se integró a la cultura chilena como sinónimo de distinción y buen gusto. Como contraparte, surgió el sombrero de medio pelo, alternativa de menor precio, muy apreciado por sectores de menores recursos económicos con interés de imitar a las elites. Estas reaccionaron con el desprecio por ese producto, cuyo nombre trasladaron a los advenedizos. Este fue el sentido despectivo que tomó en Chile la expresión "medio pelo" (Plath, 1962). Posteriormente, se perdió el sentido original que lo vinculaba con el sombrero de castor; el concepto "medio pelo" se instaló en América Latina como sinónimo de advenedizo, es decir, grupo que procura aparentar más de lo que es (Jauretche, 1966). Luego se difundieron otras palabras para significar esa idea, como "siútico" en Chile y "tilingo" en Argentina.

Mientras el "medio pelo" trataba de imitar a las elites, los campesinos optaron por una alternativa más original e identitaria. En vez de usar sombreros de "medio pelo", para asemejarse al castor, optaron por una solución innovadora e identitaria: el sombrero de paja. La idea principal era realizar con sus propias manos, un sombrero a partir de materiales disponibles en el medio, de bajo costo. Además, al utilizarse el material de descarte (paja de trigo), sus costos eran menores: un sombrero de paja valía dos o tres reales, cifra notablemente inferior a los sombreros de castor o de lana de vicuña. Ello significó extender las posibilidades del uso del sombrero a los campesinos pobres.

\section{Amanecer del sombrero de paja en Chile (década de 1740)}

En la década de 1740 se comenzaron a registrar sistemáticamente los sombreros de paja locales. En los primeros tiempos de la conquista, los escribanos españoles no estaban preparados para valorizar estos objetos. Durante mucho tiempo ignorados en los inventarios y tasaciones de bienes, junto con los utensilios de cerámica y los vasos de cacho de cabra y los asientos de calavera de vaca. Los sombreros de paja se comenzaron a registrar por expresa voluntad de los campesinos. El caso más antiguo registrado hasta ahora corresponde al teniente Ignacio Peredo, nativo de Rio Claro y vecino en la villa de San Fernando. Al redactar su testamento (1744), don Ignacio mencionó, entre sus bienes, "dos sombreros, uno de paja y otro de vicuña". Naturalmente, este se usaba para el invierno y aquel para el verano. Poco a poco, estos registros se comenzaron a generalizar en Colchagua. En Chimbarongo (1762), Miguel Valenzuela tenía cuatro sombreros de paja tasados en dos reales cada uno. En San Vicente de Tagua Tagua (1782) don José Severino García tenía dos sombreros de paja. Por su parte, don Juan José Pérez (1793) también tenía un sombrero de paja. En la villa de San Fernando (1812) doña Rosa Quinteros tenía un sombrero viejo de paja tasado en tres reales.

Estos objetos fueron rápidamente apreciados por los campesinos, y se comenzó a generar cierto mercado para su comercialización. Por ejemplo, en San Fernando (1776) doña María Rosa de Salinas tenía siete docenas de sombreros de paja pequeños, destinados al comercio.

Los campesinos se interesaron también por elaborar sombreros de paja de mayor calidad. Advirtieron que, a medida que incorporaban un trabajo más preciso y delicado, podían obtener productos de mayor calidad, y que el mercado podía valorar esa diferencia. A comienzos del siglo XIX se comenzaron a registrar sombreros de paja de mayor valor, alcanzando cifras de dos pesos por unidad. En efecto, en la estancia Tepar, distrito de Cuyonome (1805) se registró un "sombrero de paja fino en dos pesos". De esta manera se comenzó a poner en marcha el camino de los sombreros de alta calidad, con esta modesta materia prima, pero con el trabajo delicado de las manos campesinas.

\section{Las primeras chupallas (década de 1820)}

Entre las décadas de 1820 y 1840 se produjo la introducción y propagación del uso del término "chupalla" para los sombreros de paja. En la tienda de Ramón Bravo (San Fernando, 1827) se registraron "53 docenas de sombreros de chupalla a 7 reales la docena", tasados en "33 pesos con 6 reales". Poco después, Rosa Valenzuela (Rancagua, 1829) tenía "16 sombreros de chupalla". Este documento de comienzos del siglo XIX representa la verificación del uso del concepto que, más tarde, se iba a tornar raro, tal como detectó Lentz en 1910.

En la zona central de Chile se generó cierto flujo comercial de estos sombreros. En 1835 la aduana de Santiago registró el ingreso de una 
Tabla 1. Sombreros de chupalla registrados en zona central de Chile 1827-1848)

\begin{tabular}{|c|c|c|c|c|}
\hline año & Lugar & Dueño & Chupallas & Precio \\
\hline 1827 & San Fernando & Ramón Bravo & 53 docenas de sombreros de chupalla & $7 \mathrm{R} /$ docena \\
\hline 1829 & Rancagua & Rosa Valenzuela & 16 sombreros de chupalla & $\mathrm{s} / \mathrm{d}$ \\
\hline 1835 & San Felipe & & 22 sombreros de chupalla & \\
\hline 1836 & San Felipe & José Rosario García & $1 / 2$ docena sombreros de chupalla & $6 \mathrm{R} /$ docena \\
\hline 1841 & San Fernando & Juan de Dios López & $\begin{array}{l}32 \text { docenas de chupallas ordinarias } \\
5 \text { docenas de chupallas finas }\end{array}$ & $\begin{array}{l}41 / 2 \mathrm{R} / \text { docena } \\
9 \mathrm{R} / \text { docena }\end{array}$ \\
\hline 1842 & Santa Cruz & Juan Vera & $\begin{array}{l}18 \text { chupallas finas } \\
2 \text { docenas de chupallas }\end{array}$ & $\begin{array}{l}\$ 2 \text { y } 2 \mathrm{R} \\
6 \mathrm{R} / \text { docena }\end{array}$ \\
\hline 1846 & San Felipe & & 82 sombreros de chupalla & $6 \mathrm{R} /$ docena \\
\hline \multirow{2}{*}{1848} & \multirow{2}{*}{ San Fernando } & \multirow{2}{*}{ Gregorio Ríos } & 4,5 docenas & $4 \mathrm{R} /$ docena \\
\hline & & & 1 docena de chupallas delgadas & $9 \mathrm{R} /$ docena \\
\hline 1848 & San Fernando & Juan Agustín Rocha & 73 sombreros de chupalla ordinarios & \$ 1 y 7 R 3 cuartillos $R$ \\
\hline
\end{tabular}

Fuente: Archivo Nacional, Fondo Judiciales de San Fernando, de Rancagua y de Aconcagua.

partida de 22 sombreros chupalla, originaria del valle del Aconcagua. Más adelante, don José Rosario García (San Felipe, 1836) registró entre sus bienes "media docena de sombreros chupalla a seis reales docena". Unos años después, Juan de Dios López (San Fernando, 1841) registró "32 docenas de chupallas ordinarias a $4 \frac{1}{2} 2$ reales la docena, e importan 18 pesos; y cinco docenas de chupallas finas a 9 reales la docena, en 5 pesos 5 reales". Al año siguiente, Juan Vera (Santa Cruz, 1842) declaró "18 chupallas finas en 2 pesos 2 reales, y dos docenas de chupallas a 1 peso 4 reales. Estos dos últimos documentos son clave porque representa la primera evidencia de chupallas finas de la historia de Chile.

Poco a poco se comenzó a propagar la denominación "chupalla" para los sombreros de paja. Unos años más tarde, en una tienda de ramos generales de la ciudad de San Felipe (1846), entre los alimentos e indumentaria en venta, se registraron " 82 sombreros chupalla a seis reales docena". Gregorio Ríos (San Fernando, 1848) tenía "4 docenas de chupallas a 4 reales la docena, otra media docena más al mismo precio suma 2 pesos 2 reales (f $8 v$ ), una docena de chupallas delgadas en 9 reales". Juan Agustín Rocha (San Fernando, 1848) registró " 73 sombreros de chupalla ordinarios en 1 peso, 7 reales y 3 cuartillos".

Los precios de las primeras chupallas demuestran que el concepto se empleó, originalmente, para denominar los sombreros de paja más populares. El valor de tasación de 6 reales por docena, se mantuvo vigente en ambos registros. Ello refleja un producto muy barato, pues con un real se compraban dos chupallas. Este producto se acercaba al precio de los sombreros de paja populares, mencionados a fines del siglo XVIII en el corregimiento de Colchagua; y estaba muy lejos de los sombreros finos de paja, que ya existían y se tasaban a dos pesos cada uno, es decir, veinte veces más caros. Faltaba todavía un buen tiempo para que surgieran chupallas finas. El proceso fue muy gradual y lento.

\section{Conclusión}

Las chupallas que actualmente se elaboran en La Lajuela, San Pedro de Alcántara, Cutemo y Ninhue, entre otros lugares del Valle Central de Chile, son testimonios de un largo proceso histórico-cultural, iniciado hace trescientos años. Se trata de productos patrimoniales, de profundo arraigo en la sociedad campesina chilena, y asociados a otros alimentos y artesanías como la sal de Cáhuil (DO), el chamanto (DO), la chicha, el chacolí, el asoleado (DO) y el pajarete (DO). También se conecta con productos patrimoniales latinoamericanos, como el sombrero de jipijapa, en Ecuador (DO).

La tradición de las chupallas chilenas se remonta a la época colonial, cuando los españoles 
introdujeron en el Valle Central de Chile la costumbre de usar sombrero para protegerse del sol. Ante el alto costo de los sombreros de piel de castor o de lana de vicuña, la respuesta campesina fue crear los sombreros de paja (década de 1740).

El concepto de "chupalla" para denominar al sombrero de paja se comenzó a usar en la década de 1820. Originalmente, el sombrero se asoció con una planta nativa, muy apreciada por los campesinos, y utilizada con frecuencia como referencia por los viajeros. Numerosos topónimos surgieron en Chile con la palabra "chupalla", lo que demuestra el arraigo cultural que alcanzó esta planta. Al transferirse el nombre de la planta al sombrero, en poco tiempo se logró su aceptación por parte del público chileno.

En los siglos XVIII y XIX los sombreros de paja se extendieron por toda la zona central de Chile, desde el valle del Aconcagua hasta el Biobío. A su vez, dentro de este espacio, el río Maule marcó una diferencia territorial, con sombreros bonetes al sur y sombreros de paja al norte.

Originalmente, las chupallas fueron sombreros de paja, de carácter rústico, utilitario y de bajo precio. Pero la llegada de sombreros de pita y de jipijapa (en la segunda mitad del siglo XVIII) fue también un aporte significativo para estimular el desarrollo de las chupallas chilenas sobre todo de alta calidad. Desde comienzos del siglo XIX se comenzaron a hacer en Chile sombreros finos de paja, base de las actuales chupallas de alta calidad.

En Ecuador, los sombreros de jipijapa ya han sido reconocidos como Denominación de Origen, con el nombre de "Montecristi". El Estado ha elaborado una política de valoración patrimonial de esos sombreros, con medidas concretas de protección y promoción, lo que han generado beneficios considerables a los campesinos en particular, y a la identidad nacional en general. En Chile, este proceso se encuentra todavía en marcha. Los aportes de este artículo contribuirán a comprender el significado cultural de las chupallas de paja dentro del patrimonio cultural del país.

\section{Agradecimientos}

Articulo financiado por Proyecto Fondecyt 1130096 y proyecto FIC R "Rutas de la Patria Nueva" (GORE O'Higgins). Los autores desean agradecer los aportes del historiador Juan Guillermo Muñoz.

\section{Literatura Citada}

Aguilera, P.

2016. El queso de Chanco: un producto típico de la industria popular de Chile (siglos XVIII y XIX). RIVAR 3 (8): 41-63. Arancibia, M.J.

2016. "La importancia de las denominaciones de origen e indicaciones geográficas para la identidad país". RIVAR 3 (8): 267-283.

Archivo Nacional

1767. Juicio de Juan de Torres con Domingo Morales y otro sobre derecho a una mina de oro sita en el cerro de las Chupallas del mineral de Pupio en La Ligua, Fondo Real Audiencia, volumen 1327, pieza 3.

Belmar Gamboa, C.

2016. Las denominaciones de origen en Chile: desarrollo y perspectivas. RIVAR 3 (8): 253-266.

Castro, A.; León, A.; Cussen, F. y Lacoste, P.

2016. ¡Viva la chicha nueva! La chicha en la vida popular y campesina chilena. Idesia 34 (1): 77-83.

Castro, A.; Mujica, F. y Argandoña, F.

2015. Entre Pintatani y Codpa. Paisaje y productos típicos en los relatos campesinos, 1847-2013. RIVAR 2 (6): 70-86.

Cid, R.L.

2014. Chupalla de teatina de La Lajuela y Santa Cruz. Santiago, INAPI, $57 \mathrm{p}$.

Champredonde, M. y González Cosarinsky, J.

2016. ¿Agregado de valor o valorización? Reflexiones a partir de Denominaciones de Origen en América Latina. RIVAR 9 (3): 147-172.
Cubillos, F. y Muñoz, J.G.

2014. El intercambio de tierras por bienes y dinero en Colchagua durante el siglo XVII. Santiago de Chile, 129 p.

Espejo, G.

1876. El paso de los Andes. Crónica histórica de las operaciones del Ejército de los Andes para la restauración de Chile en 1817. Buenos Aires, La Facultad, 1916, 658 p.

Haig, $S$.

1817. Viaje a Chile en la época de la independencia. En: VV.AA., Viajeros en Chile 1817-1847. Santiago, Editorial del Pacífico, 1955: 11-114.

Jauretche, A.

1966. El medio pelo en la sociedad argentina (Apuntes para una sociología nacional). Buenos Aires, Peña Lillo Editora, 4a edición, 1967, 188 p.

Lacoste, P.; Castro, A.; Briones, F.; Cussen, F.; Soto, N.; Rendón, B.; Fernando Mujica, F.; Aguilera, P.; Adunka, M. Núñez, E. y Cofré, C.

2015. Vinos típicos de Chile: ascenso y declinación del Chacolí (1810-2015). Idesia 33 (3): 97-108.

Lacoste, P.; Mujica, F.; Briones, F.; y Castro, A.

2015. "El Pipeño: historia de un vino típico del sur del Valle Central de Chile". Idesia 33 (3): 87-96.

Lacoste, $\mathrm{P}$.

2017. "El queso de Tafí del Valle y el despertar de la cultura del queso en Argentina". Idesia 35 (1) (marzo 2017). 
Lacoste, P.; Pszczolkowski, Ph.; Briones, F.; Aguilera, P.; Mujica, F. y Garrido, A.;

2015. "Historia de la chicha de uva: un producto típico en Chile. Idesia 33 (2): 87-96.

Lenz, R.

1910. Diccionario etimológico de las voces chilenas derivadas de lenguas indígenas americanas, Santiago, 1910.

Maas, $\mathrm{C}$.

1847. Viaje a través de las provincias australes de la República de Chile desde enero hasta junio de 1847". En: Documentos de Revista Cóndor. Santiago, noviembre 1949/marzo 1950, 39 pp.

Olazábal, M.

1864. Episodios de la guerra de la independencia. Segunda edición: Buenos Aires, Instituto Nacional Sanmartiniano, 1978, 164 p.

Plath, O.

1962. Folclor chileno. $15^{\mathrm{a}}$ edición, $1^{\mathrm{a}}$ reimpresión: Santiago, FCE, 2013, 345 p.
Pueyrredón, M.A.

1862. Memorias inéditas de un coronel. Prólogo y notas de Alfredo Villegas. Buenos Aires, Kraft, 470 p.

Radiguet, $\mathrm{M}$.

1847. Valparaíso y la sociedad chilena en 1847. En: VV.AA., Viajeros en Chile 1817-1847. Santiago, Editorial del Pacífico, 1955: 213-254.

Riso Patrón, L.

1924. Diccionario jeográfico de Chile, Imprenta Universitaria, Santiago, $958 \mathrm{p}$.

Roig, Enrique

2011. Pinacoteca Sanmartiniana Fidel Roig Matons. Mendoza, Editorial Municipal, 103 p.

Rodríguez, Z.

1875. Diccionario de chilenismos, Santiago, 481 p.

Ruschenberg, W.

1834. Noticias de Chile (1831-1832). Santiago, Editorial del Pacífico, 1956, 120 p.

Solórzano y Velazco, A.

1657. Informe sobre las cosas de Chile, Santiago de Chile, 2 de abril de 1657. Gay (1852) II: 422-448. 